\title{
Study on Blade Fatigue Life of Rotating Power Machinery
}

\author{
Fu Xi, Kou Hai-jun and Zhang Jun-hong \\ State Key Laboratory of Engines, Tianjin University, Tianjin 300072, China
}

\begin{abstract}
The linear damage model (LDM) is widely applied in engineering calculation, but it does not consider the relationship between damage variable and load parameters. Therefore, the life prediction based on LDM is not satisfied for the aero-engine blades. Besides, it easily brings about error in predicting fatigue life by common nonlinear damage model which neglect the influence of torsional stress. Hence, a modified nonlinear continuum damage model (CDM) is put forward based on Chaboche nonlinear damage model in this research. And to determine the damage and fatigue life of TC4 material used in aero-engine blades, axial tension and compression fatigue test is conducted. Compared with LDM results, the fatigue life prediction results of the modified CDM in this work show a good agreement with the tests data. So the correctness of the modified model is verified. Finally, the fatigue life of a certain aero-engine high pressure compressor blade is predicted by the modified nonlinear continuum damage model.
\end{abstract}

\section{Introduction}

During aero-engine working, the compressor blades easily occur fatigue failure under complex loads, which is the main failure form for the blade [1-4]. Once the blade failure, a catastrophic accident will be caused in the engine and even the aircraft[5,6]. Therefore, the researches carried out for the blade fatigue failure are very significant for the online monitoring and fault diagnosis of aero-engine.

A suitable damage estimation model and fatigue life model are the key elements of further studying on life prediction of the blades. Among all the structural fatigue analysis methods, Palmgrem-Miner[7] linear damage accumulation model (LDM) is the most widely used.

$$
D=\sum_{i=1}^{n} \frac{n_{i}}{N_{i}}=\sum r_{i}
$$

where $n_{i}$ is the cycles under a certain stress level; $N_{i}$ is the failure cycles of structure under the same stress level; $D$ is damage variable. The foundation for the establishment of LDM is independent of damage produced per cycle and loading parameters.

The fatigue damage of structure is a performance deterioration process under cyclic loading. Damage variable is closely associated with loading parameters, such as stress and strain[8]. Therefore, the life prediction based on Miner's rule is not satisfied. In order to overcome the deficiencies of LDM, researchers have proposed various models based on nonlinear continuum damage theory. However, most of the models are semiempirical equations and lack of theoretical basis. In view of this problem, Kachanov[9] and Rabotnov[10] put forward the concepts of continuity degree and damage factor respectively. Marco and Starkey[11] firstly proposed a nonlinear load-dependent damage rule which allows correctly taking the effect of different loading sequences into consideration.

$$
D=\sum_{i=1}^{n} r_{i}^{x_{i}}
$$

where $x_{\mathrm{i}}$ is the variable related to loads. Some other nonlinear damage accumulation equations were also proposed in order to take into account of the influence of the multiple stress levels[12,13]. However, in those equations, load-related variables should be recalculated for different loading conditions. Although the predicted results from those equations agree with the experimental data well for some materials under certain conditions, it is complicated to calculate the corresponding coeffcients and difficult to apply in egineering.

In order to overcome the shortcoming, Chaboche [14] formulated a nonlinear continuum damage model (CDM) to describe structural performance deterioration based on fatigue fracture characteristic:

$$
d D=f(D, \sigma) d n
$$

This model mainly describes the inseparability between load parameters and damage variable. Jessen and Plumtree[15] conducted a stress-controlled fatigue test and developed a strain energy model to predict the fatigue life based on the Chaboche's work. And Cheng [16] proposed another nonlinear fatigue damage model by using the ductility exhaustion as the damage variable. Although the accuracy of fatigue damage prediction 
based on the above nonlinear damage models has been validated and widely accepted, those models are proposed to be mainly used in the situation without considering torsional stress.

In this work, a modified nonlinear model based on continuum damage theory is proposed. It suits for fatigue analysis of aero-engine compressor blades which bear bending stress and torsional stress caused by centrifugal and aerodynamic loads. And the correctness of the modified model is proved by basic conditions of continuum damage mechanics. In addition, fatigue tests are carried out to obtain parameters of mechanical property and fatigue characteristic for TC4 titanium alloy. The prediction results of fatigue life on the basis of the modified CDM have a good agreement with test results as well. Finally, the model is used to predict the fatigue life of a certain high pressure compressor blade.

\section{Fatigue test of TC4 titanium alloy}

TC4 titanium alloy is usually used to manufacture the aero-engine compressor blades due to its excellent mechanical property in high specific strength, high yield strength, high heat and corrosion resistance. In order to learn the fatigue properties of the TC4, the static tensile test is firstly carried out to obtain its mechanical parameters. Test results are listed in Table 1. The test specimen used rolled bar with 17-mm diameter (Fig. 1), $720^{\circ} \mathrm{C}$ annealing temperature, $1 \mathrm{~h}$ heat preservation and air cooling.

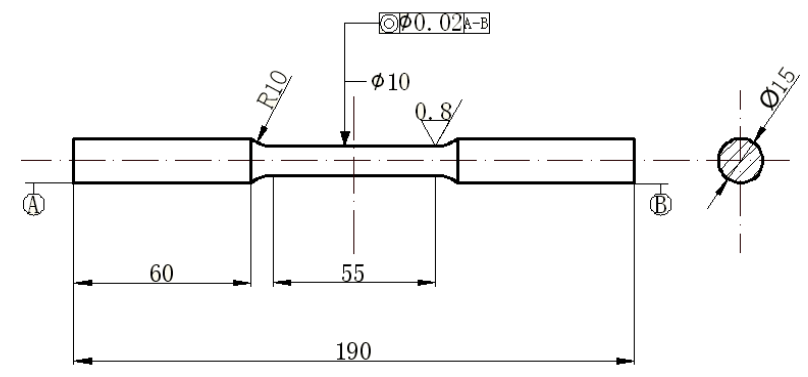

Figure 1. Static tensile test specimen.

Table 1. TC4 material properties.

\begin{tabular}{|c|c|c|c|c|}
\hline $\begin{array}{c}\text { Yield } \\
\text { strength } \\
\sigma_{\mathrm{s}} / \mathrm{MPa}\end{array}$ & $\begin{array}{l}\text { Tensile } \\
\text { strength } \\
\sigma_{\mathrm{b}} / \mathrm{MPa}\end{array}$ & $\begin{array}{c}\text { Elona } \\
\text {-tion } \\
A / \%\end{array}$ & $\begin{array}{c}\text { Reduction } \\
\text { of area } \\
Z / \% \\
\end{array}$ & $\begin{array}{c}\text { Elasticity } \\
\text { modulus } \\
E / \mathrm{GPa}\end{array}$ \\
\hline 975 & 1005 & 16 & 46 & 107 \\
\hline
\end{tabular}

In order to study the cumulative damage of TC4 material, the axial tension and compression fatigue test are also carried out at ambient temperature. According to the national standard of China GB/T 3075-2008, the test specimen is designed as Fig. 2 and made from rolled bar with 17-mm diameter. This test is designed as a defect free fatigue test. So, the test specimen's surfaces are manually polished by metallographic sandpaper to make sure that the surface without notch and defects. The test frequency is set to $2 \mathrm{~Hz}$, and stress ratio is $R=1$. The whole test results are shown in Table 2.

The fatigue limit is firstly preliminary judged through single point method which is between $300 \sim 350 \mathrm{Mpa}$.
Then 4 stress amplitudes are inserted into them, they are $310,320,330$ and $340 \mathrm{MPa}$ respectively. Finally, according to test results, fatigue limit of TC4 alloy is determined to $340 \mathrm{MPa}$. The $S-N$ curve and cross-section of fracture specimen are listed in the Fig. 3 and 4 respectively.

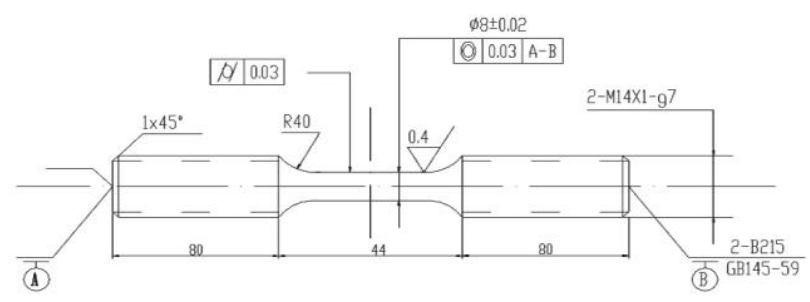

Figure 2. Fatigue test specimen.

Table 2. Axial tension and compression fatigue test results

\begin{tabular}{cccc}
\hline No. & $\begin{array}{c}\text { Maximum } \\
\text { stress }(\mathrm{MPa})\end{array}$ & Cycle $\left(\times 10^{4}\right)$ & Results \\
\hline 1 & 550 & 11 & Fractured \\
2 & 550 & 30 & Fractured \\
3 & 500 & 32 & Fractured \\
4 & 500 & 39 & Fractured \\
5 & 450 & 98 & Fractured \\
6 & 450 & 210 & Fractured \\
7 & 400 & 51 & Fractured \\
8 & 400 & 110 & Fractured \\
9 & 400 & 130 & Fractured \\
10 & 400 & 480 & Fractured \\
11 & 350 & 440 & Fractured \\
12 & 350 & 500 & Fractured \\
13 & 340 & 910 & Fractured \\
14 & 330 & 1000 & Unfractured \\
15 & 320 & 820 & Fractured \\
16 & 310 & 1000 & Unfractured \\
17 & 300 & 1000 & Unfractured \\
\hline
\end{tabular}

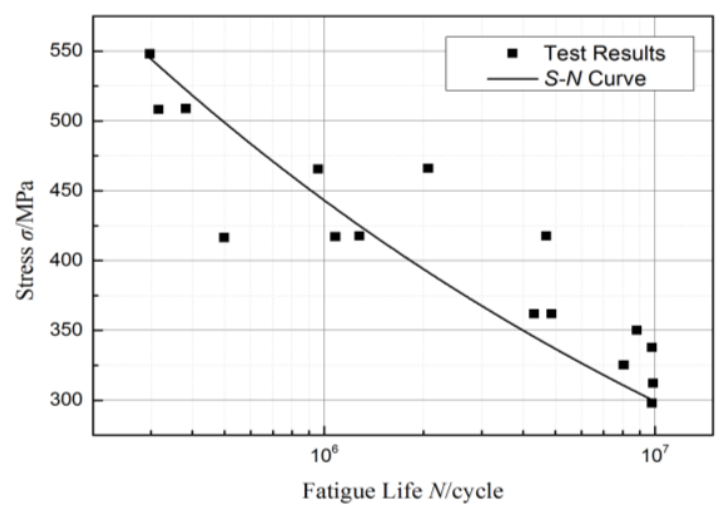

Figure 3. Test results and $S$ - $N$ curve of TC4.

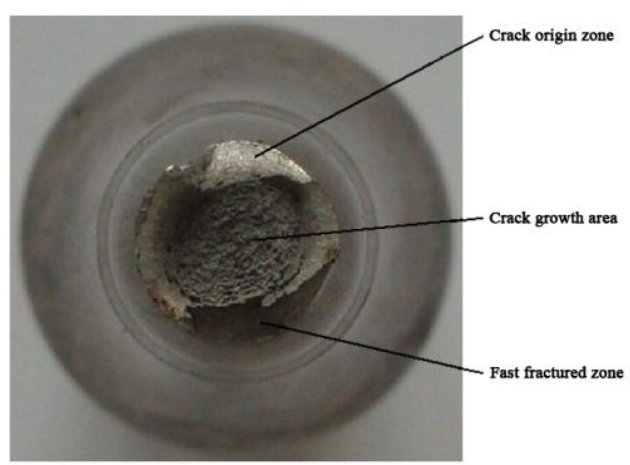

Figure 4. Section picture of fatigue test specimen. 
Fig. 4 shows the cross-section of fracture specimen, it can be seen that the fatigue fractured section of specimen can be divided into three zones: the crack origin zone, the crack growth zone and the fast fractured zone. The crack origin zone is the earliest area of the crack, the section of which is smooth, crack propagates gradually along the normal direction of the cyclic load from surface to the inner layer, and the length is about $1 / 4$ of the diameter. The section of crack growth area is rough, showing radial shape, this part occupies the vast majority of the crosssection area, in which crack growth rate is relatively stable. In the fast fractured zone, the section is wedge shaped, and the material is brittle fractured.

\section{Nonlinear continuous damage model}

For simple uniaxial fatigue problem, Chaboche proposed the following equation based on Eq.(3):

$$
d D=\left[1-(1-D)^{1+\beta}\right]^{\alpha}\left[\frac{\sigma_{a}}{M\left(1-b \sigma_{m}\right)(1-D)}\right]^{\beta} d N
$$

where $\beta, M_{0}$ and $b$ are the material parameters; $\sigma_{\mathrm{m}}$ is mean stress; $\sigma_{\mathrm{a}}$ is stress amplitude; $\alpha$ is the parameter related with loads and damage:

$$
\begin{aligned}
& \alpha=1-H\left\langle\frac{\sigma_{\max }-\sigma_{1}\left(\sigma_{\mathrm{m}}\right)}{\sigma_{\mathrm{u}}-\sigma_{\max }}\right\rangle \\
& \sigma_{1}\left(\sigma_{\mathrm{m}}\right)=\sigma_{\mathrm{m}}+\sigma_{\mathrm{I}_{0}}\left(1-b \sigma_{\mathrm{m}}\right)
\end{aligned}
$$

where $\sigma_{\mathrm{u}}$ is ultimate tensile strength; $\sigma_{10}$ is fatigue limit for a fully reversed loading conditon; $H$ is material parameter, and $\langle x\rangle=\left\{\begin{array}{l}0, x \leq 0 \\ x, x>0\end{array}\right.$. Damage variable $D$ is regulate 0 to represent the initial undamaged state and it is set to $D=1$ when the structures occurs fatigue failure.

The stress distribution of the compressor blade is very complex. The single axis fatigue model can not effectively supply a accurate prediction results of blade damage. So the model correction must be made. Considering the compressor blade working conditions and its structure characteristics, there are three kinds of vibration mode which include torsional, axial and tangential vibration. Duo to the complex aerodynamic loading, the torsional vibration of the blade will be promoted during the blade rotating. And the blade itself has the initial torsion angle, the effect of the torque on the damage must take into account ${ }^{[17]}$.

According to the fourth strength theory:

$$
\sigma_{\mathrm{B}}=\left(\sigma_{n}^{2}+3 \sigma_{t}^{2}\right)^{\frac{1}{2}}
$$

where $\sigma_{\mathrm{B}}$ is total stress; $\sigma_{\mathrm{n}}$ is normal stress; $\sigma_{\mathrm{t}}$ is shear stress; Substituting formula (7) into (4), it can be obtained:

$$
d D=\left[1-(1-D)^{1+\beta}\right]^{\alpha}\left[\frac{1-R}{2} \frac{\left(\sigma_{B}^{2}+3 \sigma_{t}^{2}\right)^{\frac{1}{2}}}{M\left(1-b \sigma_{m}\right)(1-D)}\right]^{\beta} d n(8)
$$

Taking the whole process of material damage into account, on the basis of integral of upper formula from $D=0$ to $D=1$, the fatigue life expression under arbitrary level of load with loading parameters as independent variable can be obtained as:

$$
N_{f}=\frac{1}{1-\alpha} \frac{1}{1+\beta}\left[\frac{2}{1-R} \frac{M\left(1-b \sigma_{m}\right)}{\left(\sigma_{B}^{2}+3 \sigma_{t}^{2}\right)^{\frac{1}{2}}}\right]^{\beta}
$$

In the course of above work, no damage occurs, any damage $\mathrm{D}$ is corresponding to the number of cycles $n$ :

$$
n=\frac{1}{1-\alpha} \frac{1}{1+\beta}\left[\frac{2}{1-R} \frac{M\left(1-b \sigma_{m}\right)}{\left(\sigma_{B}^{2}+3 \sigma_{t}^{2}\right)^{\frac{1}{2}}}\right]^{\beta}\left[1-(1-D)^{1+\beta}\right]^{1-\alpha}
$$

From formula (8), the cumulative damage equation under the constant loading condition is obtained:

$$
D=1-\left\{1-\left[\frac{H\langle\sigma\rangle}{M^{\beta}}(1+\beta)\left(\frac{1-R}{2} \frac{\left(\sigma_{B}^{2}+3 \sigma_{t}^{2}\right)^{\frac{1}{2}}}{M\left(1-b \sigma_{m}\right)}\right)^{\beta} n\right\}^{-H\langle\sigma\rangle}\right.
$$

Damage accumulation model needs to meet two basic conditions $^{[18]}$ :

1) Damage is not reversible, that is, in the loading cycle, the damage value must be monotonically increasing.

$$
\frac{\partial D}{\partial n}>0
$$

2) In the case of a certain damage to the material, the relatively large load per cycle can cause more damage in the rest of the load cycle.

$$
\frac{\partial^{2} D}{\partial n \partial \sigma}>0
$$

By type (9) and (11), it can be drawn that

$$
\frac{\partial D}{\partial n}=\frac{1}{(1+\beta)(1-\alpha) N_{f}}\left(\frac{n}{N_{f}}\right)^{\frac{\alpha}{1-\alpha}}\left[1-\left(\frac{n}{N_{f}}\right)^{\frac{1}{1-\alpha}}\right]^{\frac{\beta}{1+\beta}}
$$

Thus, it can be obtained that $\frac{\partial D}{\partial n}>0$. With derivation of the upper formula, it can be proved that $\frac{\partial^{2} D}{\partial n \partial \sigma}>0$.

Therefore, the modifed nonlinear continuum damage model proposed in this paper meets basic conditions of continuum damage mechanics. It indicates that this model is rational.

In order to further prove the accuracy of the modifed CDM proposed in this paper, a finite element (FE) model (Fig. 5a) is built to analyze the stress distribution. Then the damage evolution equation is adopted to calculate the fatigue life, the stress distribution is also shown in Figure 
5b. Prediction life of specimen by making use of modifed CDM and LDM respectively, and the results are comparied with the test data, as shown in Fig. 6. It can be seen that the modified CDM is better than Miner's LDM in prediction accuracy of fatigue life, and it shows greater consistency with the test results.

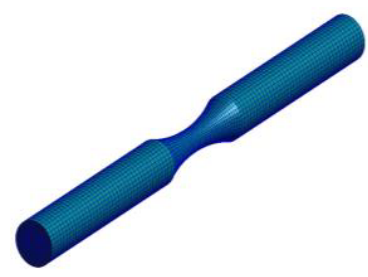

(a) Finite element model

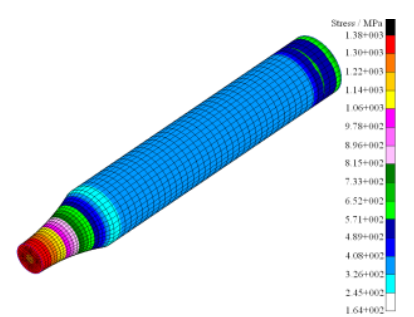

(b) Finite element results
Figure 5. FE model of test specimen.

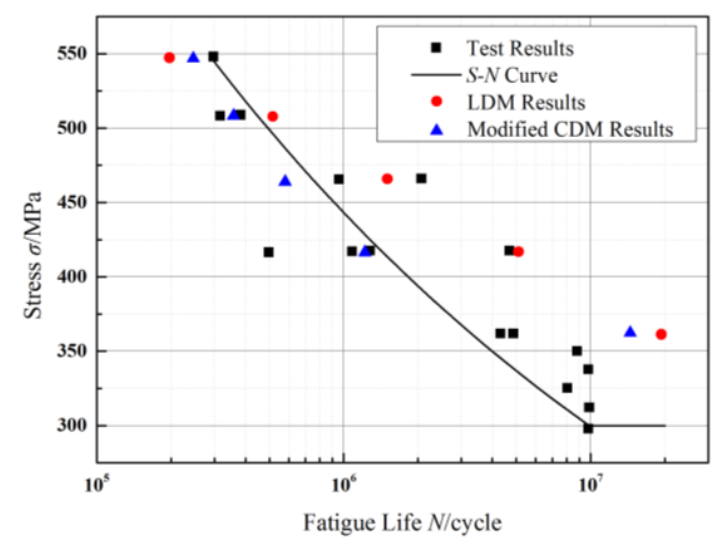

Figure 6. Comparison of life prediction results among modified CDM, LDM and test.

\section{Fatigue life prediction of high pressure compressor blades}

Bending and torsional stress of compressor blade caused by centrifugal and aerodynamic load is the main factors that lead to blade fatigue failure during aero-engine working. Hence, it is more reasonable to use the modified $\mathrm{CDM}$ proposed in this study to predict the fatigue life of compressor blade. The Fig. 7 shows assembled blade.

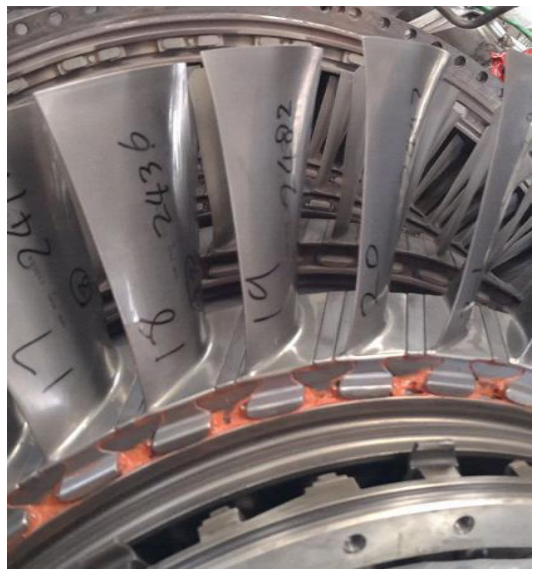

Figure 7. High pressure compressor blade
Table 3. Engine behavior.

\begin{tabular}{cccccc}
\hline \multicolumn{6}{c}{ Working conditions of high pressure compressor (RPM) } \\
\hline $\begin{array}{c}\text { Working } \\
\text { conditions }\end{array}$ & $\begin{array}{c}\text { Take- } \\
\text { off }\end{array}$ & $\begin{array}{c}\text { High- } \\
\text { speed }\end{array}$ & $\begin{array}{c}\text { Maximum- } \\
\text { continuous }\end{array}$ & Cruise & Idle \\
$\begin{array}{c}\text { Rotate } \\
\text { speed }\end{array}$ & 9561 & 9337 & 9172 & 8847 & 6966 \\
\hline
\end{tabular}

Table 4. Spectrum of power allocation for aeroengine/1000h[17].

\begin{tabular}{cccccc}
\hline $\begin{array}{c}\text { Working } \\
\text { conditions }\end{array}$ & $\begin{array}{c}\text { Take- } \\
\text { off }\end{array}$ & $\begin{array}{c}\text { High- } \\
\text { speed }\end{array}$ & $\begin{array}{c}\text { Maximum } \\
\text { continuous }\end{array}$ & Cruise & Idle \\
\hline $\begin{array}{c}\text { Time scale } \\
/ \%\end{array}$ & 1.64 & 2.13 & 18.83 & 31.62 & 45.78 \\
\hline$\%$
\end{tabular}

Based on the aero-engine test data, the whole blade working condition of the engine is simplified into five rated conditions, they are take-off, high-speed, maximum-continuous, cruise and idle (Table 3). And on this basis, the state power distribution spectrum is determined by the statistical data ${ }^{[19]}$ of power distributing for aero-engine in 1000 flight hours as shown in Table 4.

Finally, fatigue failure life of the blade under the five typical working conditions is calculated respectively. Combined with state power distribution spectrum, the blade fatigue life under the whole working condition is predicted by modified CDM. The stress distribution of some typical wording conditions is shown in Fig. 8. It can be seen that the blade root of suction surface always receives the highest stress under no matter what working condition. According to damage accumulation theory, the blade root is determined as dangerous position. And finally, the predicting life is 333628 cycles.

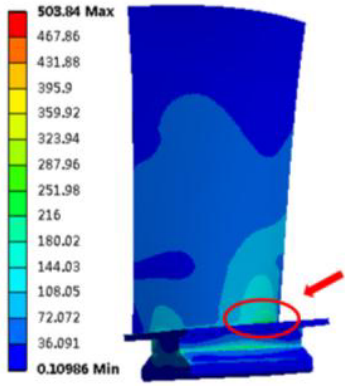

(a) Idle

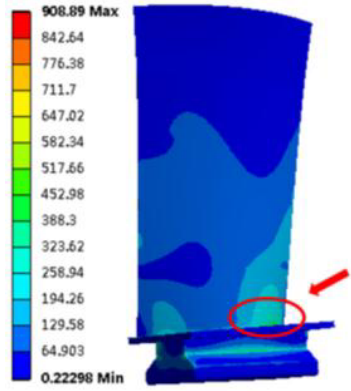

(c) Maximum-continuous

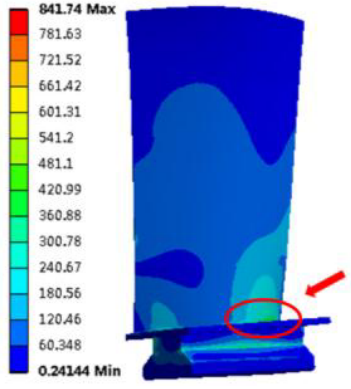

(b) Cruise

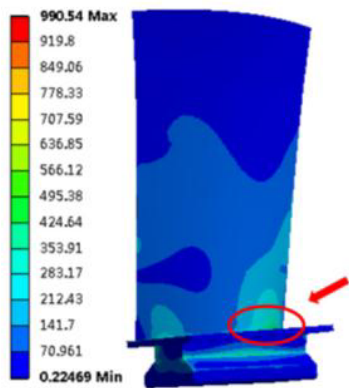

(d) Cruise
Figure 8. Stress distribution of blade. 


\section{Conclusion}

Based on the nonlinear continuum damage mechanics, a modified CDM is put forward, which takes into account the effect of torsional stress. The model has been proved to meet the basic conditions of continuum damage theory. Compared with LDM prediction results of fatigue life, the prediction result on the basis of the modified CDM proposed in this work shows a good agreement with the tests data. In addition, stress analysis and fatigue life predicion of a real compressor blade have been carried out. The blade root of suction surface always suffers the largest stress during the whole blade working condition. According to the damage accumulation theory, the fracture failure would occur in the region. And finally, the life prediction results of the blade is identified as 333628 cycles.

\section{Acknowledgements}

This work is supported in part by the National High-tech R\&D Program of China (863 Program) 2014AA0415011 and the Specialized Research Fund for the Doctoral Program of Higher Education 20130032130005. The authors are grateful for these financial supports.

\section{References}

1. Bhaumik S, Sujata M, Venkataswamy $M$, et al, Failure of a low pressure turbine rotor blade of an aeroengine. Engineering Failure Analysis, 13(2006)

2. Poursaeidi E, Aieneravaie M, Mohammadi M, Failure analysis of a second stage blade in a gas turbine engine. Engineering Failure Analysis, 15(2008)

3. Poursaeidi E, Salavatian M, Failure analysis of generator rotor fan blades. Engineering Failure Analysis, 14(2007)

4. Sreyas Krishnan S, Anish R, and Girish K E, Stress Analysis of a Rear Pressure Bulkhead of the Fuselage Structure and Fatigue Life Estimation. International Journal of Mechanical Engineering and Robotics Research, 2(2013).

5. Sujeet $\mathrm{S}$ Narkhede and A Pateriya, Design and Analysis of Turbine Blade of Engine - A Review.
International Journal of Mechanical Engineering and Robotics Research, 3(2014).

6. Vaibhav R Pannase and A M Shende, Optimization Design, Modeling and Structural Analysis of Wind Mill Blade. International Journal of Mechanical Engineering and Robotics Research,2(2013).

7. Miner M. A, Cumulative damage in fatigue. Journal of applied mechanics, 12 (1945)

8. Fatemi A, Yang L, Cumulative fatigue damage and life prediction theories: a survey of the state of the art for homogeneous materials. Int. J. Fatigue, 20(1998)

9. Kachanov L M, Time of the rupture process under creep conditions. Isv. Akad. Nauk. SSR. Otd Tekh. Nauk, 8(1958)

10. Rabotnov Y N, On the equation of state of creep, Proceedings of the Institution of Mechanical Engineers, Conference Proceedings. SAGE Publications, 178(1963)

11. Marco S M, Starkey W L, A concept of fatigue damage. Trans. ASME, 76(1954)

12. Manson S. S, Halford G. R, Practical implementation of the double linear damage rule and damage curve approach for treating cumulative fatigue damage. Int. J. Fract. 17(1981)

13. Rabotnov Y. N, Creep problems in structural members. North Holland, Amsterdam. (1969)

14. Chaboche J. L, Lesne P. M. A, Non-linear Continuous Fatigue Damage Model. Fatigue \& fracture of engineering materials \& structures, 11(1988)

15. Jessen S. M, Plumtree A, Continuum damage mechanics applied to cyclic behaviour of a glass fibre composite pultrusion. Composites, 22 (1991)

16. Cheng G, Plumtree A. A, Fatigue damage accululation moedl based on continuum damage mechanics and ductility exhaustion. Int. J. Fatigue. 20 (1998)

17. Wu Ying, Fracture and fatigue, Wuhan: China University of Geosciences Press, (2008)

18. Shang Deguang, Yao Weixing, Research on the cumulative model of single axis nonlinear continuous fatige damege. Journal of Aeronautical, 16(1998)

19. Yu Zhufeng, Design of structure and strength for nickel base single crystal turbine blade, Beijing: Science Press, (2008) 